\title{
Construcción de Significados Culturales a partir de los Tejidos que Elaboran las Mujeres Nasa de Tierradentro como estrategia de Comunicación para la Pervivencia
}

\author{
Cultural Meanings Construction from the Tissues made by Nasa Women from \\ Tierradentro as a Communication Strategy for Survival
}

Yeny Finscue Chavaco ${ }^{1}$

\section{Resumen}

El presente artículo resalta el papel de las mujeres Nasa de Tierradentro Cauca, en el proceso de comunicación ancestral y en la construcción de significados culturales, por medio de los tejidos que elaboran y que han sido una estrategia de comunicación para la pervivencia de los pueblos y el territorio. Se expone el sentido del tejido como una práctica esencial donde se representan símbolos y signos cargados de significados, construidos a través de la interacción comunitaria, de los hechos históricos, las recomendaciones de sabedores y sabedoras, las orientaciones y la proyección del pueblo. De la misma manera se expresa el tejido en la lengua Nasayuwe "umna" como la capacidad de poner en conexión las tres dimensiones, lo espiritual, el cuerpo y el territorio entre los que se interactúa cotidianamente y se transita en espiral con orientación de la luna y el sol, en el ser-estar, ir, llegar y retornar con criterio de dignidad e identidad. Por ultimo se expresa la importancia del aprendizaje colectivo como la estrategia que mantienen los pueblos y que se le denomina pedagogías comunitarias desde las cuales se ha mantenido el uso y la valoración de los tejidos en el tiempo y en el espacio para la pervivencia de nuestros pueblos.

Palabras clave: Tejido; símbolos; mujeres; territorio; interacción; comunicación; pedagogías comunitarias.

\section{Abstract}

This article highlights the role of Nasa women from Tierradentro, Cauca, in the process of ancestral communication and in the construction of cultural meanings, through the tissues they make and that have been a communication strategy for the survival of the peoples and the territory. The sense of the fabric is exposed as an essential practice where symbols and signs loaded with meanings are represented, constructed through community interaction, historical facts, and the recommendations of knowledgeable

1 Máster en Comunicación Intercultural con Enfoque de Género y Licenciada en Educación. Dinamizadora de la Universidad Indígena UAIIN-CRIC, Colombia. Correo Electrónico: yyfinscue@gmail.com; ORCID: https://orcid.org/oooo-0002-6559-7309

Recibido: 21/05/2019 Aprobado: 29/07/2019 
persons, the orientations and the projection of the people. In the same way, the fabric in the Nasayuwe language "umna" is expressed as the ability to connect the three dimensions, the spiritual, the body and the territory between which it interacts daily and spirals in the direction of the moon and the sun, in being-being, going, arriving and returning with criteria of dignity and identity. Finally, the importance of collective learning is expressed as the strategy that the peoples maintain and that is called community pedagogies from which the use and appreciation of tissues has been maintained over time and in the space for the survival of our peoples.

Keywords: Tissues; symbols; women; territory; interaction; communication; community pedagogies.

\section{Introducción}

Tierradentro es un territorio que se caracteriza por su gran biodiversidad y su diversidad cultural potenciada por prácticas espirituales de hombres y mujeres comprometidos, como el caso de los integrantes del "semillero de investigación pedagógica "KIWE UMA"" un proceso de formación cultural, que se esfuerza por retornar a las raíces del pueblo Nasa y que ha sido la inspiración para realizar este CRISSAC.

Las comunidades Nasa hemos sufrido un proceso de olvido de prácticas culturales, causado por el despojo y la imposición. Pese a ello, aún se conserva parte del conocimiento ancestral, gracias a la insistencia de las mujeres Nasa, en mantener la lengua "Nasa Yuwe", el Tul y el sentido del tejido representativo de la simbología cosmogónica del territorio.

Este artículo resalta el sentido del tejido en tres dimensiones importantes: el tejido espíritu, el tejido cuerpo y el tejido territorio. El primero, tiene expresión en las energías de los tejidos y sus representaciones simbólicas mediante la sensibilidad con la espiritualidad; el segundo, prioriza el conocimiento del cuerpo como primer territorio habitado; el tercero, muestra que los tejidos que elaboran las mujeres Nasa representan y ratifican el territorio. Los tres tejidos se articulan y forman parte del sistema de comunicación del pueblo Nasa fortalecido mediante la pedagogía comunitaria.

\section{Palabra orientadora de las autoridades culturales y teóricas}

El proceso de Crianza, Siembra de Sabidurías y Conocimientos y este articulo tiene como orientación principal el aporte de la sabiduría propia de la gente del mismo territorio, en diálogo con la parte de la literatura de otras culturas que se conectan con el accionar de los pueblos indígenas y que permiten un respeto epistémico. 


\section{La comunicación para la permanencia de los pueblos}

El Plan de vida, para muchos pueblos indígenas del Cauca sustenta la proyección en el tiempo y en el espacio de su vivencia, y tiene como elemento principal la participación colectiva de las propuestas de acuerdo a la palabra de origen, entendida esta última, como "el tejido del pensamiento que ayuda a comunicar" (NxunTumbo, comunicación personal, 16 junio 2017). Ese comunicar según Dora Muñoz "es "Puutx We'wnxi Uma Kiwe", la comunicación desde la madre tierra. Como una relación espiritual y natural que transmite mensajes de vida y convoca a todos los seres, a cuidar y defender la Madre Tierra" (Muñoz, 2016,p.9). De esta manera, la comunicación en el contexto de los pueblos indígenas es un principio y un mandato para permanecer en el territorio, dialogar y permitir esa relación armónica, la cual no es otra cosa que estar contentos.

Estar contentos, estar alegres posibilita que la energía de la vida circule para mantenernos atentas y atentos a los lenguajes de la madre tierra. Lenguajes como el UMNA que significa tejido, la mayora Josefina valora este lenguaje porque considera que "el tejer es unir, y hacer tramas que se convertirán en símbolos que muestran la vida, el territorio y las relaciones que se generan en él" (Josefina Díaz, comunicación personal, octubre 2015). La intención de preservar esta práctica ancestral, radica en la posibilidad de asegurar la comunicación para la maduración física y espiritual, porque es en esta etapa en la que se adquiere conocimiento frente al cuerpo de cada persona que elabora un tejido y se configura la memoria de un territorio.

\section{Una mirada hacia el ser mujer en el contexto Nasa}

Dentro de las diferentes culturas ser mujer tiene una connotación particular, debido a la desigual relación entre hombres y mujeres, aunque históricamente los dos desempeñan un papel importante tanto en preservar la cultura, como en la creación, recreación y transformación de los valores, las normas y las prácticas culturales de una sociedad, estos mismos elementos también han determinado dichas desigualdades. La Organización De Las Naciones Unidas, para La Educación, La Ciencia y La Cultura (UNESCO, 2014) considera que estas relaciones, evolucionan con el tiempo y en las que influye una matriz de factores socioeconómicos, políticos y culturales [...] Además los cambios en la combinación de esos factores pueden afectarlas de manera positiva o negativa (p.104). Por ejemplo para las mujeres de los pueblos indígenas, la época colonial transformó de manera negativa las relaciones, si bien en algunos pueblos existía el patriarcado, no se consideraba a la mujer como un objeto, sin embargo con el choque cultural debido a la invasión europea se generó un afianzamiento de la estructura patriarcal dominante. Al respecto, Lorena Cabnal citada por Gargallo (2014) afirma: 


\section{GÉNERO E INTERCULTURALIDAD}

No sólo existe un patriarcado occidental en Abya Yala [...] sino también afirmamos la existencia milenaria del patriarcado ancestral originario, el cual ha sido gestado y construido justificándose en principios y valores cosmogónicos [...]. Este patriarcado tiene su propia forma de expresión, manifestación y temporalidad diferenciada del patriarcado occidental. A su vez fue una condición previa que existía en el momento de la penetración del patriarcado occidental durante la colonización, con lo cual se refuncionalizaron, fundiéndose y renovándose [...] (p. 22).

Los debates son continuos y las miradas diversas frente a una historia que nos ha tocado enfrentar y nombrar, para definirnos ante la adversidad, sin embargo, las mujeres indígenas desde los territorios planteamos reivindicar nuestros aportes, a través del diálogos honestos y horizontales con lo masculino dando una mirada integral al ser mujer, como fuente de sabiduría y conocimiento.

\section{La interacción comunitaria dentro del pueblo Nasa.}

La interacción social hace posible que se actúe y se reaccione frente a otros grupos. De acuerdo con Goffman (1961, p.115), "nuestras acciones se enmarcan en contextos sociales y les atribuimos significados y finalidades relacionados con lo social. De esta mandera, los significados se van construyendo socialmente y en ese mismo sentido la interacción simbólica es producto de ella". Parafraseando a Blumer, citado por Forner (1988), el interaccionismo simbólico es el resultado de la interacción social y el intercambio de significados en lo cotidiano.

Desde la mirada de mayoras y mayores Nasa, es en la interacción con el entorno, la madre tierra y demás seres que la habitan, en donde se construyen los significados. En el caso de la interacción espiritual, ésta conecta el sentir y la energía vital que mueve al mundo. En palabras de Palacio (2015), "es una especie de fuerza interna que dinamiza las dimensiones del ser humano" (p.459).

\section{Materiales y métodos}

El presente artículo muestra parte del camino del CRISSAC recorrido en territorio Nasa de Tierradentro Cauca.

Son cuatro criterios que nos orientan al tejer en rombo o en espiral; se parte de la conciencia del ser, en un territorio marcado por la cultura y por el andar del tiempo; transita en el ir, buscando, lugares, tiempos y espacios; el llegar, visitando, ofrendando alimentos, tejidos y encontrando la palabra, la memoria, las personas, los animales y las plantas quienes nos comparten las sabidurías y conocimientos de la tierra; en el retorno, es el pensamiento en espiral que enrolla y desenrolla, cargado de sabidurías y conocimientos, los cuales se comparten en la medida que se va transitando por el 
camino, para empezar nuevamente el ciclo del ser y estar, ir, llegar y retornar. En cada ciclo y en cada tramo los sentidos están presentes y al igual que la luna y el sol, orientan todo el proceso.

\section{El camino de la CRISSAC}

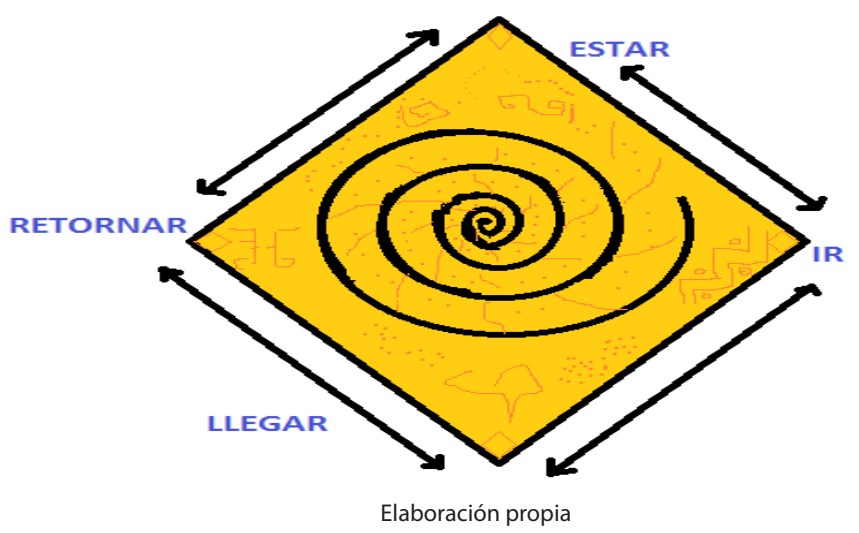

Estrategias para la crianza y siembra de las sabidurías y conocimientos

\section{Se retoman las formas propias para transitar en un camino sostenido milenariamente}

La minga del CRISSAC: Es el proceso en el cual la comunidad hace el ejercicio de cooperación y pone la fuerza y energía común para realizar una actividad, en este caso se empodera de la propuesta CRISSAC y se decide determinar estrategias para avanzar, las y los integrantes del semillero "kiwe uma" consideramos el camino y la búsqueda sobre el sentido del tejido como parte del compromiso que tenemos con la tierra. En esta dirección, se llevaron a cabo encuentros con mujeres tejedoras de distintas comunidades, espacio en el que se debatió y reflexionó sobre el papel de la mujer dentro de la cultura, se contó con la participación de mayores espirituales, quienes ayudaron a orientar desde la parte cosmogónica

Diálogos: Cuando realizamos el CRISSAC, uno de los caminos más importantes considerados es la interacción directa con los y las tejedoras, con mayores y mayoras, con las voces de niñas y niños, la conversa. Con el diálogo, como palabra orientadora, se aconseja, enseña, recomienda, y se comparte desde la tradición oral. 
Tulpas familiares: Las familias del semillero "kiwe Uma" tienen como práctica vivencial la tulpa, para que sus integrantes reconozcan las prácticas culturales y potencien la lengua propia. En estos espacios sagrados, se tejió, dialogó, se compartieron alimentos, música, y se aseguró el intercambio intergeneracional.

Recorridos territoriales: Para entender muchos de los símbolos que se plasman en los tejidos fue necesario recorrer varias comunidades, sitios sagrados como los Hipogeos o tumbas en San Andrés de Pisimbala, algunos sitios de potenciación de dones, como la Laguna Juan Tama y Piedra Mona. Los recorridos dieron fuerza y energía, además a cada lugar visitado se llevaron tejidos como ofrenda.

\section{Resultados y discusión}

\section{Tejiendo sabidurías y conocimientos}

En todo este camino de aprendizaje nos adentramos a plantear el proceso del sentido del tejido UMNA, como el entramado de acciones, pensamientos y sentimientos, que ayudan a conservar, recordar y vivenciar el conocimiento de la madre tierra, desde el origen, la semilla, el corazón (Nasa üus), es decir desde la espiritualidad, que conecta con la raíz de lo ancestral, por tanto, el sentido del tejido parte de una dinámica conectada al territorio como ente vivo que da sus manifestaciones de acuerdo a la relación del tiempo orientado por el sol y la luna, que de acuerdo a nuestra cosmovisión es femenina y marca el ritmo de nuestras acciones cotidianas.

La siguiente ilustración nos muestra el recorrido y las orientaciones dadas por autoridades culturales y espirituales del pueblo Nasa para la potenciación del sentido del tejido en la dimensión del tejido espiritual, tejido cuerpo y tejido territorio: 


\section{El camino de la luna Ate Dxij}

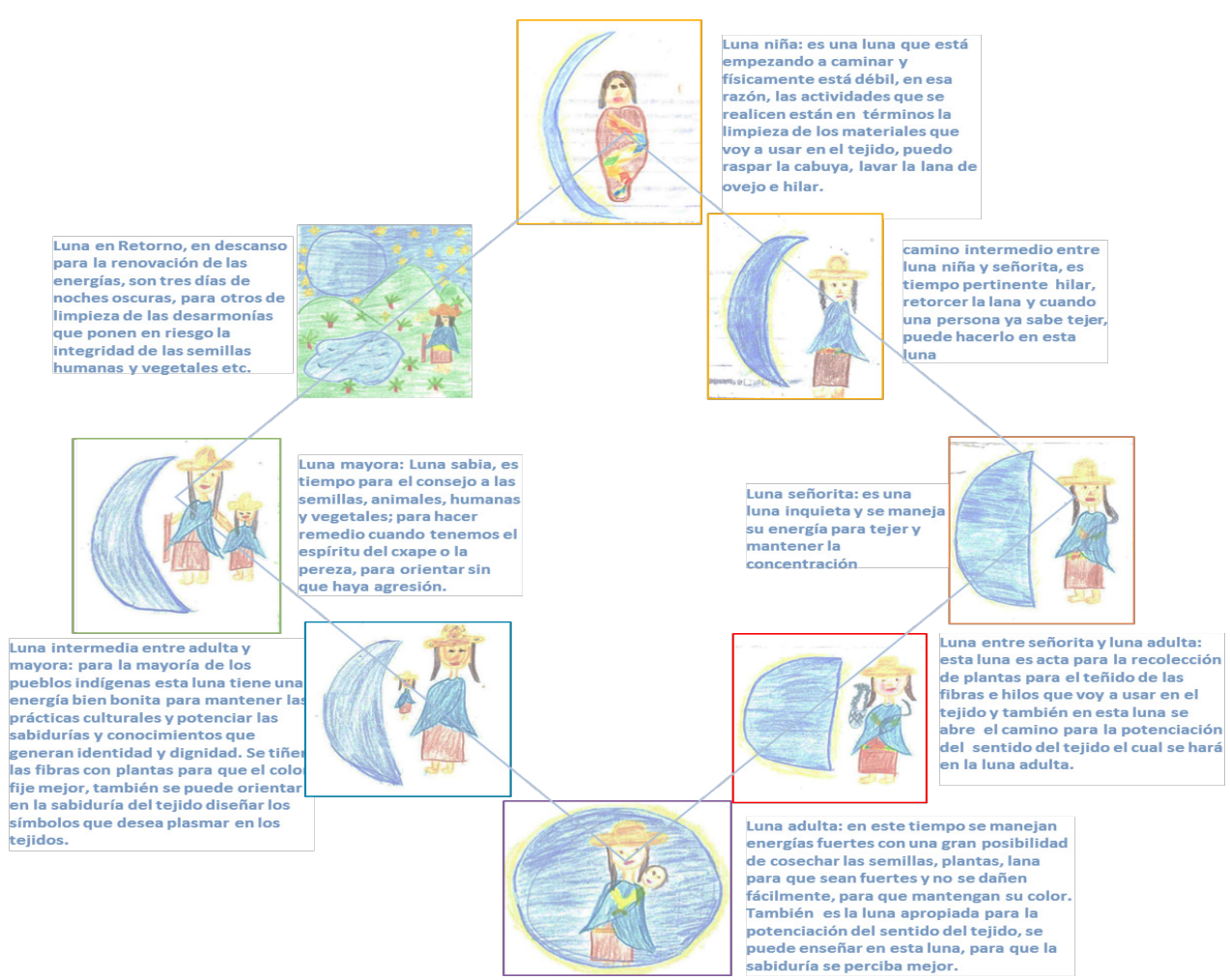

Fuente de elaboración: niñas y niños del semillero de investigación pedagógica "Kiwe Uma". Tierradentro

\section{Tejiendo espíritu}

Las energías que fluyen a través de la tierra son la fuerza que mantiene el equilibrio natural, estas energías son valoradas y potencializadas por los mayores y mayoras que mediante la memoria transmiten saberes a nuestras comunidades. En muchos pueblos y en el caso Nasa esa fuerza energética que mueve y da sentido le llamamos espiritualidad, por la cual existe la comprensión del cosmos y las relaciones que en él se generan. Este entendimiento se produce por medio de la activación de los sueños, las pulsaciones del cuerpo, escucha, visión, olfato, tacto entre otros, que permiten identificar, construir, valorar el significado de lo que nos rodea.

Según cuenta la compañera Carmen Vitonas, "los símbolos grabados con figuras (...), recrean la naturaleza, el cuerpo humano, las comidas y la autoridad". (Vitonas, comunicación personal, octubre 2015). De esta manera, mediante los símbolos los y las mayoras construían la memoria de los pueblos. 
La simbología se expresa con el término "Nasa Uus pwisnxi", que la mayora Carmen citada por Yule (2015) traduce como "la imagen desde el corazón del ser", el símbolo es la "imagen presencia y revelación de un espíritu Nasa" (p. 22). Este espíritu o energía se inscribe en el tejido para recordarnos nuestro origen. Mientras tanto, es en la tradición oral donde las historias se van tejiendo comunitariamente y ayudan a fundamentar las prácticas de los pueblos para este caso el sentido del tejido.

\section{Tejiendo cuerpo}

Cuando una persona Nasa aprende de los conocimientos ancestrales, es porque justo antes de ser concebida la semilla, se realizan una serie de procedimientos, si es hombre o mujer, para que su desarrollo físico, mental y espiritual esté en equilibrio y no genere situaciones problemáticas más adelante. Desde la cosmovisión de nuestro pueblo, cada persona tiene un compromiso con la tierra y en este sentido se van encaminando las acciones para que pueda asumir con responsabilidad y con gusto lo que hace en el transcurso de su existencia. Desde la lógica del compañero Leónidas Urriaga, "el conocimiento se aprende de acuerdo a la orientación que hacen los astros y el guía espiritual, no todos los cuerpos son iguales y dependiendo donde vivan se conoce distinto" (Urriaga, comunicación personal, 12 diciembre 2016). En este aspecto el territorio y las personas configuran su conocimiento, le dan sentido y transforman sus prácticas según las indicaciones de los mayores y mayoras con experiencia espiritual y social.

Cada cuerpo es un territorio, el que hay que defender y cuidar por eso desde antes de nacer hasta que parte a otro territorio se relaciona con los tejidos para fortalecerse. Si es hombre o si es mujer tiene ciertas prácticas que posibilitan la maduración del cuerpo de manera armónica, es así que cuando son bebes se enchumban o envuelven con un tejido llamado "Taw o Chumbe", cinta tejida con lanas de diferentes colores. La Mayora Josefina Achicue comparte:

El chumbe es el símbolo territorial y también representa el arco iris, en el se escribe la vivencia del pueblo Nasa para no perder la memoria. Se usa para fajar al niño pequeño y fortalecer la parte corporal; es decir, lo enrollan o fajan con chumbe para que el niño crezca derecho sin problemas físicos y corporales. El chumbe tiene la función de impregnar la historia con sus símbolos y colores, el niño al ser enchumbado día a día le refuerzan la identidad. (Achicue, comunicación personal, 14 agosto 2017).

Cada tejido fortalece parte de nuestro cuerpo, en la medida que vayamos madurando física y espiritualmente, los niños y niñas empiezan a observar, e interpretar las diferentes situaciones que se dan en su entorno, las imágenes, las figuras y símbolos, se constituyen en elementos claves de aprendizaje y significantes en la vida del niño y niña. 
Dentro de los tejidos que se realizan están también las mochilas de cabuya y de lana de ovejo, las cuales representa el territorio y el útero de la mujer, por eso recomiendan tejerlas, porque da fuerza, equilibrio, salud, conocimiento y sabiduría. La jigra representa el territorio, el útero de la mujer Nasa, y es símbolo de la fertilidad que permite la existencia de la humanidad y las semillas.

La práctica del tejido exige una serie de normas culturales que tienen que ver con la formación de la mujer y del hombre, tanto antes de la concepción como en el traspaso al otro territorio; en este camino que recorre se adquiere el conocimiento y la sabiduría para poder relacionarse de manera armónica con la dualidad o complemento, es decir, lo femenino con lo masculino, lo material como lo espiritual.

Los y las Nasa continuamos el ciclo de existencia y los cambios biológicos y espirituales en nuestro cuerpo se presentan a medida del andar del tiempo, por ejemplo en el caso de niñas a señoritas es el tiempo en el que la menstruación se presenta y a través de rituales y de un actividad constante con el tejido es como se puede tener un desarrollo pertinente, Neity Cuscue, una Niña de 16 años cuenta "después de los 14 años aun no me había llegado la menstruación, ya llevo tejiendo 3 pares de jigra y empecé hacer la cuetandera y el chumbe, además mi mama me recomienda que no esté cerca a los nacimientos de agua después de las $5 \mathrm{PM}$, cuando tejo me concentro y pienso en mi cuerpo, en aprender y poder ayudarle a mi mamá". (Neity Cuscue, Comunicación personal, 11 octubre 2017). Bajo esta narrativa nos podemos dar cuenta del valor cultural que representa para las niñas el tejido, acompañado del conocimiento y cuidado del cuerpo. Del mismo modo Leodeimar Urriaga, realiza el tejido del sombrero quien manifiesta "me gusta tejer, ahora soy más responsable, cuido a mi hermano menor y mi papá dice que si sigo tejiendo la voz no me va a cambiar tan rápido" (Leodeimar Urriaga, comunicación personal, 11 octubre 2017) es en la acción practica como los mismos seres van siendo conscientes de su vida, el tejer con sentido facilita el conocimiento propio.

Los ciclos avanzan haciéndose más complejos el requerimiento cultural tanto para hombres como para mujeres reconociendo las dinámicas de trasfondo familiar y comunitario, ya que los tejidos tienen la función de aportar en el campo sociocultural de referencia para las otras generaciones.

\section{Tejiendo territorio}

La mayora Carmen Vitonás, nos recuerda que cada tejido que se realiza esta articulado al territorio, Uma Kiwe que representa los distintos espacios y con ello cada uno de los pueblos tiene su manera de figurarlo, en la medida que va transcurriendo el andar del tiempo las comunidades construyen símbolos y a través de la espiritualidad y la cosmovisión es como se refuerzan más. 
(...) La cosmovisión es fundamento del sentido de relación que tenemos con la naturaleza y con los otros seres terrenales o espirituales, por lo tanto, es la que determina nuestra identidad cultural. Este sentido de relación cultivado por los pueblos indígenas está basado en la construcción de una espiritualidad viva, ligada al diario vivir, por tanto la espiritualidad para los pueblos indígenas no es algo intangible, sino algo que se vive diariamente, algo con lo que se conversa y que tienen una transcendencia tal que conforma culturas. (UAIIN, 2018, p.39).

Los tejidos se convierten en el mismo territorio, mientras, las montañas, ríos, estrellas, luna, sol, lagunas, trueno y animales son conocimientos representados en cada tejido, en una especie de cartografía ancestral que legitima el espacio en el cual se habita. A manera de ejemplo, el tejido de la cuetandera representa la matriz de la mujer y el territorio, ya que lo describe detalladamente para que las y los Nasa no olviden la norma natural del cuidado de la tierra. Para el Mayor Manuel Sisco, este tejido se "constituye en la fuerza espiritual para los Kiwe The o mayores culturales", porque se tejen las 7 etapas de vida que tienen como Nasa (Sisco, comunicación personal, enero 2018). Los colores aluden al proceso de interculturalidad, cada color es una etapa de vida, un tiempo en el camino de la luna y una energía distinta en el sentido de la particularidad de cada color.

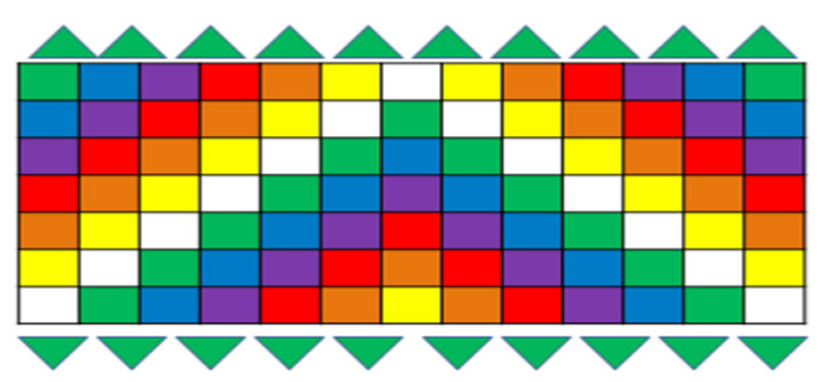

Elaboración propia

La cuetandera tiene un corazón donde parte la vida del territorio, donde la palabra de origen y la memoria de los pueblos esta para enrutarnos en la vida cultural del pueblo Nasa, cada cuadro tiene la función de conectar una etapa con la otra, en un orden cósmico de cooperación para que exista la armonía. Luego vienen unos anillos protectores, o espíritus que protegen al territorio para que las energías que circunden logren armonizarse y mantener la convivencia. Seguidamente están diseñados los triángulos o lanzas en señal de alerta ante cualquier situación de desarmonía, de aquí depende el apego territorial y el principio cosmogónico de ser parte de un territorio, de cuidarlo y defenderlo. 


\title{
Las mujeres fuerza espiritual, física y territorial
}

Las mujeres indígenas en el transcurso del tiempo han aportado significativamente en la parte económica, política y cultural, remitiéndonos a la historia del pueblo Nasa, la organización sociopolítica tenía una estructura matriarcal, las mujeres orientaban manteniendo el orden social en una relación de convivencia entre lo femenino y lo masculino, la mujer era considerada Nej U'sxa, que puede traducir mujer diosa, poderosa porque por su carácter femenino lograba mediar en situaciones difíciles, pero también reaccionar ante agresiones y guerras.

Las mujeres ejercían un campo de poder en términos de guiar y se movían bajo el principio de Kwe dxi (camino del varón):

\begin{abstract}
"Había paridad y el hombre no era considerado más que las compañeras, ni al contrario, sino que caminaba a la par, existieron varias cacicas entre las que recordamos esta la Gaitana, su nombre original el "Wey Tama" que significa la fuerza del bastón, esta mujer oriento al pueblo Nasa y lo defendió con valentía justo en la época de la llegada de los invasores a Tierradento". (Manuel Sisco, comunicación personal, 22 octubre, 2017)
\end{abstract}

En esa idea las mujeres Nasa han conservado la espiritualidad, la lengua y el tejido a través de procesos de resistencia y empoderamiento, multiplicado los saberes y conocimientos desde el rol de educadoras, lideresas, consejeras, liberadoras de la tierra, compartiendo su vivencia, el sentir y la creatividad para que sea posible la comprensión de la espiritualidad y los significados de símbolos plasmados en los tejidos.

\section{La construcción de significados culturales}

La interacción que tenemos las personas y la naturaleza es la que hace que podamos significar nuestros símbolos para plasmarlos en los tejidos que principalmente las mujeres hemos realizado. El plasmar es la representación, es la sistematización de hechos que han pasado y que han marcado el devenir de los pueblos, esta representación se hace por medio de símbolos que colectivamente se le dan un significado.

Todo este cumulo de sabidurías ha sido posible porque los pueblos tienen su forma propia de compartir esos saberes, conocida como pedagogía comunitaria y entendida como el proceso interactivo de las acciones de las personas, que representan un saber que transita en lo colectivo y es retroalimentado por [...] las mismas comunidades, es dinámico y se transforma en coherencia al espacio y tiempo (Finscue 2015, p.40).

En esa misma dirección Catherine Wals afirma que: 
(...) que lo pedagógico adquiere su razón y sentido político, social, cultural y existencial, (...) fuertemente arraigado a la vida y a la memoria colectiva de los pueblos indígenas y afrodescendientes (...), (Wals 2013, p.25).

La pedagogía comunitaria comprende el ser que comparte sabidurías y conocimientos como un dinamizador que fortalece la memoria de los pueblos. Para Freire, "el ser comunitario aprende rompiendo con las imposiciones y por su misma condición hace valer sus conocimientos y experiencias que el mundo de la vida le ha permitido acumular en diversos espacios y tiempos. (Freire 1993, p.156).

En este sentido, las mujeres han podido aprender y compartir para que el conocimiento de los pueblos perviva en el tiempo, son ellas las mejores pedagogas, al igual que la Cacica Cxapik y Gaitana, mantienen la dignidad del conocimiento y sabiduría que permite vivir en cada espacio, en cada tiempo y con otros seres. Los tejidos que elaboran las mujeres Nasa componen el sistema de comunicación propia, a través del lenguaje simbólico, que en comunidad se ha ido construyendo y fortaleciendo con las pedagogías comunitarias de los pueblos.

\section{Conclusiones}

Encontrar tiempos y espacios que fortalezcan las prácticas culturales, es un reto grande, caminarlos es una hazaña y tejerlos es movilizar el pensamiento originario. Se parte de una mirada integral del territorio, que se mueve con la sabiduría de la luna y el sol, los cuales son la ruta para acercarnos a las sabidurías y conocimientos que tiene el sentido del tejido. Por tanto la integración de la práctica del andar del tiempo Nasa y la práctica ancestral del tejido de las mujeres se hace fundamental para la comprensión cosmogónica de los símbolos representados en los tejidos.

Los tejidos ancestrales responden a demandas espirituales, del cuerpo y el territorio; lo espiritual exige poner alerta todos los sentidos, el relacionamiento con los espíritus de los tres espacios y la canalización de energías naturales que posibilitan la vida y hacen posible ser ordenados con nuestras acciones; el tejido cuerpo es entendernos como parte de la madre tierra, somos la representación de ella como ese primer territorio que habitamos y que potencializamos a través del tejido.

Los símbolos plasmados en los tejidos se constituyen en la escritura ancestral, en el lenguaje que comunica a la colectividad, es decir a los diferentes seres que habitan el territorio. El tejido como lenguaje ancestral hace parte del sistema de comunicación propia, la cual se mantuvo gracias al conocimiento y sabidurías de las ancestras, a las mayoras tejedoras que mediante la pedagogía comunitaria han compartido las sabidurías del sentido del tejido, resaltando el valor cultural, pero también el auto reconocimiento de las mujeres tejedoras, hiladoras y constructoras de la dignidad de todos y todas bajo el principio del Wet Wet Finzenxi, permanecer contentos, con alegría en el territorio. 


\section{Agradecimiento}

Esta publicación obtuvo el financiamiento de: NORAD a través del Proyecto RUIICAYHIOA INTERCULTURAL COMMUNICATION LINKAGE PROGRAMME (Número 1300624).

\section{Lista de referencias}

Asociación Juan Tama. (2012). Plan de vida. Inzá Cauca.

Forni, P. (1988). Las metodologías de George Herbert Mead y Herbert Blumer. Universidad del Salvador.

Finscue Y. (2015). La pedagogía comunitaria como proceso de enseñanza del arte del tejido. Tesis pregrado, universidad UAIIN. Cauca Colombia.

Freire P. (1993). Pedagogía de la esperanza. Siglo XXI Editores. México.

Gargallo, F. (2014). Feminismos desde el Abya Yala. Ciudad de México.

Goffman, E. (1961). "Role distance". En Encounters: Two Studies in the Sociology of Interaction. Indianápolis, Bobbs-Merril.

Mercado, A. y Zaragoza, L. (2011). La interacción social en el pensamiento del sociólogo.

Muñoz, D. (2016). "PUUTX WE’WNXI KIWE UMA" comunicación desde la Madre Tierra: "camino de sabidurías que nos convocan a liberarla, para que la vida exista". Tesis de Maestría. URACCAN. Nicaragua.

Palacio, C. (2015). La espiritualidad como medio de desarrollo humano.

UAIIN (2018). Tejido de Pedagogía de las Artes. CRIC. Cauca Colombia

UNESCO (2014). Indicadores UNESCO de cultura para el desarrollo. Paris Francia.

Walsh, C. (2013). Pedagogías Decoloniales.

Wilches, G. (2005). Proyecto Nasa: La construcción del plan de vida de un pueblo que sueña. Bogotá Colombia.

Yule, M. (2010). La metamorfosis de la vida. Proyecto Nasa Toribio. 